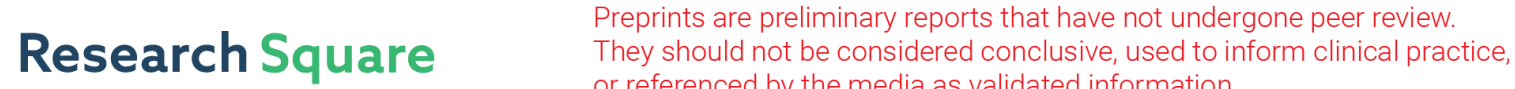 or referenced by the media as validated information. \\ Knowledge About Syphilis and Its Oral Manifestations Among Dental Students: Cross- sectional Study
}

\section{Antonio Carlos Pacheco Filho}

Universidade Estadual Paulista Julio de Mesquita Filho

Artênio José Isper Garbin

Universidade Estadual Paulista Julio de Mesquita Filho

Natália Cupertino Pires

Universidade Federal do Espirito Santo

Karina Tonini dos Santos Pacheco ( $\nabla$ kktonini@yahoo.com.br)

Universidade Federal do Espirito Santo https://orcid.org/0000-0002-4687-6062

Cléa Adas Saliba Garbin

Universidade Estadual Paulista Julio de Mesquita Filho

Research article

Keywords: Syphilis, dental students, oral manifestations

Posted Date: May 26th, 2020

DOI: https://doi.org/10.21203/rs.3.rs-30272/v1

License: (c) (i) This work is licensed under a Creative Commons Attribution 4.0 International License.

Read Full License 


\section{Abstract}

Background:Clinical manifestations of the syphilis can occur in the mouth and in the perioral region. This study aimed to investigate the knowledge about syphilis and its oral manifestations among dental students and to discuss the role of the dentist in prevention and control of this disease.

Methods:This is a cross-sectional study carried out with dental students from a Public University. Data collection was performed by a semi-structured questionnaire containing 16 questions answered by students in classroom. Analyses of absolute and relative frequency were performed. To perform association among variables, the Chi-square test (or Fisher's exact test with Yates correction) was performed with $5 \%$ significance level.

Results:Only 40 (46.4\%) students correctly answered the question about disease stages. Almost all participants answered that syphilis has oral manifestations; however, only 44 (25.7\%) answered the question correctly. Regarding differential diagnoses of other oral lesions, only 63 (37.3\%) reported knowledge on this subject. There was a statistically significant association between student's educational level and knowledge about the etiological agent $(p=0.000)$, clinical manifestations $(p=$ $0.000)$, disease stages $(p=0.000)$, oral manifestations $(p=0.000)$ and drugs $(p=0.005)$ related to the disease.

Conclusions:Participants showed important gaps in their knowledge about syphilis and its oral manifestations. Our findings, together with the increased number of new cases of the disease in the world, reinforce the need for training dental professionals with knowledge about early diagnosis, effective treatment and follow-up of syphilis cases.

\section{Background}

Syphilis represents a chronic worldwide infection on the rise. This infection affects more than 10 million people worldwide per year [1], with $60 \%$ or more of cases occurring in men who have sex with men, being strongly associated with HIV co-infection and high-risk sexual behavior [2].

The disease presents four distinct stages that are characterized by particular symptoms, clinical manifestations, and infectivity levels: primary, secondary, tertiary, and latent syphilis. Clinical manifestations can occur in the mouth and in the perioral region and primary and secondary lesions are highly contagious. For this reason, in many cases, the dentist is the professional who makes the diagnosis of this pathology, and therefore plays an extremely important role in contributing to the effectiveness of diagnosis, control and treatment, through the identification of its signs and symptoms, guiding the patient in relation to procedures, treatment support and follow-up [3].

In addition, the possibility of non-sexual transmission makes the dentist to be among health professionals most at risk of contamination, as accidental contact with saliva and blood may occur during clinical practice. In addition, the risk is greater when considering that 9 out of 10 patients with 
syphilis do not present any clinical manifestations, although they remain infectious and that in most cases lesions are painless [4].

Considering the importance of academic formation that allows the insertion of dentists in multiprofessional teams for diagnosis and treatment of sexually transmitted infections (STIs) [5] and that the knowledge may influence attitudes and behaviors [6], the aim of this study was to investigate the knowledge about syphilis and oral manifestations among dental students and to discuss the role of the dentist in prevention and control of this disease.

\section{Methods}

This is a cross-sectional study conducted with dental students from a Brazilian Public University. The sample universe was composed of students enrolled in the second, third, fourth and fifth years in the first semester of 2019. Students in the first year and first semester of the second year (third period) were excluded for not having taken the Stomatology discipline, which officially addresses the content discussed in this study. A pilot study was carried out with first-year students.

Data collection was performed by a semi-structured questionnaire, which was answered by students in classroom, containing 16 questions about identification (sex, age), school year and aspects related to knowledge about syphilis (what is it, agent etiology, forms of transmission, clinical manifestations, disease stages, oral manifestations, differential diagnoses and drugs used for treatment).

Data were statistically analyzed with the IBM SPSS Statistics for Windows 19.0 software package. Analyses of absolute and relative frequency were performed. To perform the association among variables, the Chi-square test (or Fisher's exact test with Yates correction) was performed with $5 \%$ significance level.

This project was approved by the Ethical Committee of the Department of Science, Federal University of Espírito Santo, Brazil. All participants who agreed to participate in the research signed the Free and Informed Consent Form.

\section{Results}

The number of research participants was 169, 129 (75.1\%) of whom were female and $139(81.9 \%)$ aged under 25 years (Table 1 ). 
Table 1

Characteristics of participants $(n=169)$.

\begin{tabular}{|lll|}
\hline Variables & & $\mathbf{n}(\%)$ \\
\hline Sex & Female & $129(76.3 \%)$ \\
\cline { 2 - 3 } & Male & $40(23.7 \%)$ \\
\hline Age & Less than 25 years & $139(81.9 \%)$ \\
\cline { 2 - 3 } & Between 25 and 29 years & $26(15.7 \%)$ \\
\cline { 2 - 3 } & Between 30 and 34 years & $2(1.2 \%)$ \\
\cline { 2 - 3 } & Between 35 and 39 years & $2(1.2 \%)$ \\
\hline Educational level & Early years of dentistry course (second and third years) & $86(51.0 \%)$ \\
\cline { 2 - 3 } & Final years of dentistry course (fourth and fifth years) & $83(49.0 \%)$ \\
\cline { 2 - 3 } & &
\end{tabular}

All students reported to know what syphilis is and 167 (98.8\%) received information about the disease during the undergraduate course. When asked about the etiological agent, $135(79.9 \%)$ answered Treponema pallidum. Regarding forms of transmission, 166 (98.2\%) students claimed to know them, and $160(94.7 \%)$ considered unprotected sexual contact as one of the main transmission forms (Table 2).

Of the total number of students, $84(50.0 \%)$ reported to know the clinical manifestations of syphilis, of those, $66(78.8 \%)$ reported that one of the most common syphilis lesions is hard chancre. Only $40(46.4 \%)$ students correctly answered the question about disease stages. Almost all participants answered that syphilis has oral manifestations; however, only 44 (25.7\%) answered the question correctly, that is, they reported that the appearance of chancre is common in the primary disease stages (Table 2).

Regarding the different diagnoses with other oral lesions, only 63 (37.3\%) claimed to know them, while $110(63.3 \%)$ knew that the main form of treatment is penicillin (Table 2). 
Table 2

Numerical and percentage distribution of knowledge about syphilis and oral manifestations among dental students.

Questions $\quad n(\%)$

Knowledge on the forms of transmission

Forms of transmission

Sexual contact

160

$(94.7 \%)$

Vertical

124

(73.4\%)

Dental office

101

(59.8\%)

Etiological agent

N. gonorrhoeae

5

(3.0\%)

C. trachomati

6

T. pallidum

135

(79.9\%)

T. vaginalis

16

H. ducreyi

$0(0 \%)$

Knowledge about the clinical manifestations of syphilis $n$ (\%)

84

$(50.0 \%)$

About clinical manifestations $\mathrm{n}$

(\%)

One of the most common lesions is soft chancre

10

$(14.3 \%)$

It is not possible to observe skin changes

2

$(2.4 \%)$

One of the most common lesions is hard chancre

66

$(78.4 \%)$

Thrush is commonly observed in these patients

5

$(5.9 \%)$

About disease stages $n(\%)$ of hard chancre
The disease is more contagious in the third stage with the presence

The third stage may not show symptoms

It is not possible to observe skin changes such as spots 5 $(4.8 \%)$

There is no risk of contamination in the primary phase 
Knowledge about oral clinical manifestations of syphilis $\mathbf{n}(\%)$

About oral manifestations $\mathrm{n}$ (\%)

There is no risk of contamination in the primary phase

In the secondary phase, the appearance of syphilitic gumma is common

In the tertiary phase, the appearance of hard chancre is common, which is the healing of lesions in the primary and secondary phase

62

The appearance of hard chancre is common in the primary phase

\title{
Knowledge on differential diagnoses
}

\section{Not differential diagnoses of syphilis}

\author{
Lichen Plan
}

Polymorphic erythema

Soft chancre

Hairy Leukoplakia

Herpes

\section{Main medication} used for treatment

\section{Penicillin}

Azithromycin

Erythromycin

Fluconazole

Acyclovir

There was a statistically significant association between student's educational level in the Dentistry course and knowledge about etiologic agent $(p=0.000)$, clinical manifestations $(p=0.000)$, disease stages $(p=0.000)$, oral manifestations $(p=0.000)$ and drugs $(p=0.005)$ related to syphilis. Students enrolled in the early years had better knowledge about the disease than students in the final years (Table 3). 
Table 3

Association among variables related to knowledge about syphilis and the educational level of dental students

\begin{tabular}{|c|c|c|c|c|c|c|}
\hline \multirow[b]{2}{*}{ Variable } & \multicolumn{2}{|c|}{$\begin{array}{l}\text { Early years of dentistry } \\
\text { course }\end{array}$} & \multicolumn{2}{|c|}{$\begin{array}{l}\text { Final years of dentistry } \\
\text { course }\end{array}$} & \multirow[b]{2}{*}{$\begin{array}{l}\text { Chi- } \\
\text { square }\end{array}$} & \multirow[b]{2}{*}{$\begin{array}{l}\mathrm{p}- \\
\text { value }\end{array}$} \\
\hline & $\mathbf{N}$ & $\%$ & $\mathbf{n}$ & $\%$ & & \\
\hline \multicolumn{7}{|c|}{ Etiological agente } \\
\hline Knows & 80 & $93.0 \%$ & 55 & $66.3 \%$ & 17.189 & 0.000 \\
\hline $\begin{array}{l}\text { Does not } \\
\text { know }\end{array}$ & 6 & $7.0 \%$ & 28 & $33.7 \%$ & & \\
\hline \multicolumn{7}{|c|}{ Clinical manifestations } \\
\hline Knows & 51 & $59.3 \%$ & 15 & $18.1 \%$ & 28.458 & 0.000 \\
\hline $\begin{array}{l}\text { Does not } \\
\text { know }\end{array}$ & 35 & $40.7 \%$ & 68 & $81.9 \%$ & & \\
\hline \multicolumn{7}{|c|}{ Syphilis stages } \\
\hline Knows & 34 & $41.5 \%$ & 6 & $7.2 \%$ & 24.491 & 0.000 \\
\hline $\begin{array}{l}\text { Does not } \\
\text { know }\end{array}$ & 48 & $58.5 \%$ & 77 & $92.8 \%$ & & \\
\hline \multicolumn{7}{|c|}{ Oral manifestations } \\
\hline Knows & 38 & $44.2 \%$ & 6 & $7.2 \%$ & 28.68 & 0.000 \\
\hline $\begin{array}{l}\text { Does not } \\
\text { know }\end{array}$ & 48 & $55.8 \%$ & 77 & $92.8 \%$ & & \\
\hline \multicolumn{7}{|c|}{ Differential diagnosis } \\
\hline Knows & 3 & $3.5 \%$ & 7 & $8.4 \%$ & - & $0.205^{\star}$ \\
\hline $\begin{array}{l}\text { Does not } \\
\text { know }\end{array}$ & 83 & $96.5 \%$ & 76 & $91.6 \%$ & & \\
\hline \multicolumn{7}{|l|}{ Drugs } \\
\hline Knows & 65 & $75.6 \%$ & 45 & $54.2 \%$ & 7.569 & 0.005 \\
\hline $\begin{array}{l}\text { Does not } \\
\text { know }\end{array}$ & 21 & $24.4 \%$ & 38 & $45.8 \%$ & & \\
\hline
\end{tabular}

\section{Discussion}


This study showed that dental students, in general, have inadequate knowledge about syphilis. Moleri et al. [5] reported that although many universities present their curricula aimed at general knowledge, they often have not adequately prepared students to recognize and diagnose complex clinical conditions, such as those presented by syphilis.

In this perspective, few students know the oral manifestations of syphilis. In agreement with our research, Wu et al. [6] investigated the knowledge about occupational blood-borne pathogen among Chinese dental students and found that less than half of participants were able to answer which are the main oral manifestations of syphilis.

The main oral manifestations are hard chancre, mucous plaques and gumma. Oral chancre in primary syphilis is characterized as a painless ulcer, measuring 1 to 2 centimeters, with firm and rolled border [7]. It manifests as a single ulcer, usually on the lip or, more rarely, on the tongue [8]. Secondary syphilis presents multiple and generally symptomatic ulceration [9]. In these cases, lesions are maculopapular, affecting the hard palate and, sometimes, the soft palate ${ }^{8}$. Gumma, associated with tertiary syphilis, initially manifests as one or more painless swelling, especially on the hard palate [10].

Recognizing the oral manifestations of syphilis is a crucial role of the dentist, because as oral lesions are highly contagious, the reliability of the correct diagnosis helps in the adequate management, reduces the infection chain and reduces the risk of transmission to health professional [11]. It is worth mentioning that the form of transmission least reported by participants was through the dental practice. This occurs when correct professional practice is not established [3, 4].

In addition, a small percentage of students reported knowledge about the differential diagnoses of oral manifestations of the disease. Indeed, studies have shown that the diagnosis of oral manifestations of syphilis represents a challenge for professionals because they have a variety of clinical appearances [12, 13]. The fact that some characteristics may be similar to other conditions is of concern, and if diagnosis is not performed in the primary and secondary stages, the patient is exposed to the risk of complications related to the tertiary stage [12].

Our study also showed that students enrolled in the early years of the Dentistry course had better knowledge about etiologic agents, clinical manifestations, disease stages, oral manifestations and drugs than students enrolled in the last two years. The only association that was not statistically significant was in relation to differential diagnosis, where knowledge was low for both groups.

Unlike this research, studies that investigated the knowledge of dental students about HIV / AIDS [14-16] and occupational of blood-borne pathogens $[17,18]$ showed that knowledge about some aspects was greater among students with higher educational level. Keser et al. [14] justified this finding by the fact that the older group may have gained more experience over the years and was exposed to larger number of patients compared to the younger group. Brailo et al. [18] reported that this finding can be explained by the fact that in the clinical phase, at the beginning of the clinical practice in each department, students are introduced to this content again. 
Usually, in the fist years of the Dentistry course, students have the Stomatology discipline, which addresses the content about syphilis and it's oral manifestations. However, we consider it essential that this content is addressed in other moments and disciplines throughout the undergraduate course, so that students are aware of all aspects that involve the disease, regardless of the educational level they are attending.

A fact that attracted attention was that studies on knowledge about the transmission of blood-borne pathogens among dental students conducted by Myers et al.[17] and Brailo et al.[18], published in 2012 and 2011, respectively, did not address syphilis. The study by Wu et al. [6], published in 2016, included the disease, probably due to its increasing prevalence worldwide. Syphilis started to become evident again a few years ago, so many clinicians do not consider syphilis in their differential diagnosis of oral lesions [19]. In Brazil, the disease has shown significant increase in incidence since 2010.

The number of participants who recognized penicillin as the drug of choice for treatment was less than expected. Penicillin became universal as an effective way of treating syphilis and was responsible for the significant decrease in the epidemiological numbers of the disease. This positive result in coping with the disease left a significant gap in medical and dental education [5].

The study has limitations due to its cross-sectional design. Another limitation was the limited number of articles published on the topic with dental students, which makes our research original. Our findings, together with the increased number of new cases of the disease in the world, reinforce the need for training dental professional with knowledge about early diagnosis, effective treatment and follow-up of syphilis cases. As the main form of infection transmission is sexual, its diagnosis and treatment must consider socio-cultural and ethical scope. The disease has repercussions on the affected people's way of life, and this issue should also be addressed during the undergraduate courses [20].

It is necessary to raise the student's interest not only in the clinical aspect of the disease, but also in care issues. Improving students' knowledge can be an effective way to increase the willingness to treat patients [6]. However, it is necessary to seek educational methods that can improve student's experience and learning skills.

\section{Conclusions}

Participants showed important gaps in their knowledge about syphilis and its oral manifestations. Knowledge was associated with student's educational level during the undergraduate course. Our results support a call to improve syphilis and its oral manifestations education at Dental Education Institutions.

\section{Declarations}

\section{Ethics approval and consent to participate}


This project was approved by the Ethical Committee of the Department of Science, Federal University of Espírito Santo, Brazil (number: 2.801.172). All participants who agreed to participate in the research signed the Free and Informed Consent Form.

\section{Consent for publication}

Not applicable.

\section{Availability of data and materials}

All data generated or analysed during this study are included in this published article

\section{Competing interests}

The authors declare that they have no competing interests

\section{Funding}

"This study was financed in part by the Coordenação de Aperfeiçoamento de Pessoal de Nível Superior Brasil (CAPES) - Finance Code 001"

\section{Authors' contributions}

These authors contributed equally to this work.

\section{References}

1. Sukumaran A. Resurgence of syphilis: Challenges for dental care providers. J Dent Res Rev. 2016;3:115-6.

2. Centers for Disease Control and Prevention. Sexually Transmitted Disease Surveillance 2017. Atlanta: U.S. Department of Health and Human Services; 2018.

3. Little JW. Syphilis: An update. Oral Surg Oral Med Oral Pathol Oral Radiol Endod. 2005;100:3-9.

4. Leuci S, Martina S, Adamo D, Ruoppo E, Santarelli A, Sorrentino R, et al. Oral Syphilis: a retrospective analysis of 12 cases and a review of the literature. Oral Dis. 2013;19:738-46.

5. Moleri AB, Lobo CB, Santos FR, Silva EJ, Gouvêas CVD, Moreira LC. Differential diagnosis of manifestations of syphilis and aids with lichen planus in mouth: case report. J Bras Doenças Sex Transm. 2012;24:113-7. 
6. Wu L, Yin Y-L, Song J-L, Chen Y, Wu Y-F, Zhao L. Knowledge, attitudes and practices surrounding occupational blood-borne pathogen exposure amongst students in two Chinese dental schools. Eur J Dent Educ. 2016;20:206-12.

7. Lu DJ, Zbar A. Atypical presentation of syphilis as an aphthous ulcer. CMAJ. 2017;189:E748.

8. Minicucci EM, Vieira RA, Oliveira DT, Marques SA. Oral manifestations of secondary syphilis in the elderly -a timely reminder for dentists. Aust Dent J. 2013;58:368-70.

9. Lim JHL, Chio MTW. Watch the Tongue. Ann Acad Med. 2015;44(12):575-6.

10. Leão JC, Gueiros LA, Porter SR. Oral manifestations of syphilis. Clinics. 2006;61:161-6.

11. Garbin CAS, Pacheco Filho A, Garbin AJI, Pacheco KTS. The dentist's role in syphilis prevention and control. Rev Soc Bras Med Trop. 2019;52:e20180252.

12. Fregnani ER, Perez-de-Oliveira ME, Parahyba CF, Perez DEC. Primary syphilis: an uncommon manifestation in the oral cavity. J Formosan Med Assoc. 2017;116:326-7.

13. Santos IS, Bastos DB, Valente VB, D'Vila SP, Tjioe KC, Biasoli ER, et al. Reemerging syphilis: diagnosis from oral lesions. J Oral Diag. 2017;2(1).

14. Keser G, Göcüncü N, Pekiner FN. Assessment of knowledge level about acquired immune deficiency syndrome and patient approaches of dental students. Niger J Clin Pract. 2019;22:1259-65.

15. Ryalat ST, Sawair FA, Shayyab MH, Amin WM. The knowledge and attitude about HIV/AIDS among Jordanian dental students: (Clinical versus pre clinical students) at the University of Jordan. BMC Res Notes. 2011;4:191.

16. Lorosa AH, Pereira CM, Hussne RP, Silva-Boghossian CM. Evaluation of dental students' knowledge and patient care towards HIV/AIDS individuals. Eur J Dent Educ. 201;23:212-9.

17. Myers JE, Myers R, Wheat ME, Yin MT. Dental students and bloodborne pathogens: occupational exposures, knowledge, and attitudes. J Dent Educ. 2012;76:479-86.

18. Brailo V' Pelivan I, Škaricić J, Vuletić M, Dulcić N, Cerjan-Letica G.Treating patients with HIV and Hepatitis $B$ and $C$ infections: Croatian dental students' knowledge, attitudes, and risk perceptions. J Dent Educ. 2011;75:1115-26.

19. Siqueira CS, Saturno JL, Sousa SCOM, Silveira FRX. Diagnostic approaches in unsuspected oral lesions of syphilis. Int J Oral Maxillofac Surg. 2014;43:1436-40.

20. Kassebau DK, Tedesco LA. The 21st-Century Dental Curriculum: a framework for understanding current models. J Dent Educ. 2017;81:eS13-2. 